\title{
Promoting Inclusive Education Through the Lens of Learning Disabilities
}

\author{
Elizabeth Santhanam \& Wendy Paulusz \\ Monash University
}

The Faculty of Engineering in an Australian university collaborated with a central academicleducational development unit to design and deliver a teaching development program for all engineering teaching assistants (TAs). This paper discusses the approach taken to promote inclusive education in engineering in a situation with competing priorities. One of the strategies employed in the program aimed at enhancing the TAs' awareness of the diversity of learning styles and abilities within their student cohort with particular reference to students with a learning disability or a mental health condition. Research (Mortimore, 2003) has shown that certain learning styles can be characteristic of a learning disability or mental health condition. A standard learning styles inventory tool was introduced so TAs could identify their own preferences and realize the learning environment can be 'disabling' when there is a mismatch between a learning preference and teaching style. Through discussions and activities, TAs developed inclusive teaching strategies which could facilitate learning for all students. The program provided opportunities to discuss other issues related to diversity among students and other members of the university community, and effective communication skills. Changes in the attitude of the engineering TAs and faculty towards this program are discussed.

\section{Introduction}

$I^{\mathrm{n}}$ nduction of teaching assistants (TAs) to support teaching and learning in higher education is a common practice in the US and Canada. The expectation in North America is that all graduate/postgraduate students who plan to become academics in universities and colleges should gain their initial teaching ex- perience through the role of a TA. Programs to support the teaching development of TAs are generally provided through a central unit in the institution. The preparation for future academics to teach is less structured in many other countries, such as Australia. Frequently, TAs are expected to have the knowledge 
and skills to teach a subject by virtue of having been an undergraduate student in the relevant discipline area. While many Australian universities are attempting to introduce a more structured and standard approach to support the teaching development of TAs, and the teaching development programs generally touch upon student diversity, rarely do the programs attempt to discuss issues associated with learning disabilities. This essay outlines a teaching development program that introduced not only the more obvious issues of diversity (e.g., cultural and language background), but also the issues related to learning disabilities. The program was designed and offered by a central support unit for all TAs in the Faculty of Engineering at an Australian university.

\section{Background}

The outcomes of two major projects in Australia, that investigated support for those who are employed by universities to teach on a temporary (non-tenure track) basis, showed that few institutions provided comprehensive support for teaching development of the sessional teachers (Australian Learning and Teaching Council [ALTC], 2008; Australian Universities Teaching Committee [AUTC], 2003). The first study reported that TAs were often employed as tutors or demonstrators with very little support for professional development (AUTC, 2003). The second study found an improvement in the support made available to TAs, but the support was still far from comprehensive (ALTC, 2008). Another investigation that focused on the "provision of professional development for university teaching" identified different types of programs or courses, and states that:

despite the central importance of teaching in higher education, and our growing understanding of how to support the development of teaching expertise, the way we prepare and support staff for their teaching role in universities remains largely unsystematic and ad hoc. (Dearn, Fraser \& Ryan, 2002, p.1)
Monash University is the largest and most international university in Australia, with six onshore campuses and two offshore campuses. In 2006, the Faculty of Engineering at Monash University decided to collaborate with the Centre for the Advancement of Learning and Teaching (CALT) in order to provide a teaching development program for all TAs in the faculty. The TAs were required to attend the program which was offered over two days before the start of the semester in 2007. The program consisted of four modules and there were no electives. Each module was about two and half hours long to explore the following themes: facilitating learning, diversity and inclusive teaching, communication skills, and planning for teaching and classroom management. While there were changes in the sequence of modules and the module facilitators in 2007 , the program content and delivery have been relatively stable. The topic of 'learning disability' was introduced in the identification of student diversity. The rest of this essay will explain the exploration of learning disability in the program and the module's pathway from skepticism to interest among the TAs and others in the Faculty of Engineering.

\section{Why Consider 'A Learning Disability?'}

Recognizing the obvious diversity in student backgrounds, in particular with the phenomenal growth in international students at both undergraduate and postgraduate levels, teaching development programs for TAs have included a component to discuss diversity (Dysievick, 2007). However, the focus has tended to be on cultural and gender related issues; rarely do they touch on the hidden differences, such as learning preferences. Nevertheless, it has been found that the accessibility to university and successful completion of courses by students with a disability, are largely dependent on the attitudes and competencies of teaching staff (Norlander, Shaw, \& McGuire, 1990). Successful educational outcomes, particularly for those students experiencing difficulties with learning depend on teachers adapting instruction to accommodate individual difference (Glaser, 1977; 
Mortimore, 2003). As there has been an increase of $88.1 \%$ in the number of students with a learning disability since 1996 (from less than 5\% to more than $30 \%$ ), training faculty members and TAs on adopting a more inclusive teaching approach has become imperative.

\section{Promoting Awareness of a Learning Disability in the 'Diversity and Inclusive Teaching' Session}

The session, which is highly interactive, consists of a range of experiential activities and discussions. The outline of what is covered is given below.

In order to increase the TAs' awareness of diverse learners' experiences in the classroom, an empathy exercise is used. One such exercise uses an innovative computer software package that simulates visual processing difficulties, which can be experienced by both dyslexic and non-dyslexic people (Beacham \& Szumko, 2005). The purpose of this empathy exercise is to highlight how it feels to be unable to decode written (or verbal) information quickly enough and the frustration, anxiety, and tension such a situation causes especially under test conditions. However, the main focus of the session continues to be on how TAs can create a more 'enabling' and inclusive environment for all students rather than emphasizing individual learning problems students might have, as TAs are not qualified to make a differential diagnosis of individual students' needs. Before investigating features of a universal instructional design, the TAs are asked to complete a "learning styles questionnaire" based on the "Index of Learning Styles" (Felder \& Silverman, n.d.) so they can reflect on their own preferences and the diversity within the group attending the session. TAs are facilitated to reflect on how their own learning preferences influence their assumptions and expectations of the way students might receive feedback, and also influence how they instruct. TAs are then shown a DVD (a video is also available) of students discussing their learning issues (Eaton Coull Learning Group, 2003).
After the screening of the DVD, the TAs discuss the learning issues and characteristics of the students shown in the DVD. Then they work in small groups to develop strategies which would make their lesson content more accessible to diverse learning preferences, including students with a learning disability. Each small group then presents its strategies to the whole group for further discussion and comment, so that the session participants can exchange ideas, support each other, and take this learning back to their respective classrooms.

The program participants identified inclusive teaching strategies, such as giving an outline of what will be covered at the beginning of the session and summarising key points at the end; emphasizing (bold or underline) key words in written text and repeating key words during session; using graphs, charts, pictures, and models to support verbal and kinaesthetic activities; modulating voice; breaking up the session; and using humour appropriately. The session also provides a resource kit of information for teaching staff and where to go for further help. Online support is available in the form of the "Inclusive teaching for diverse learners" website which showcases inclusive teaching practices of some faculty members at Monash (Monash University, n.d.). The website also includes advice from the Disability Liaison Unit at Monash regarding equity and disability.

\section{Discussion}

Feedback from the TAs has been very positive so far; more than $95 \%$ of those who responded to the feedback survey (representing $76 \%$ program participants) said they were 'very satisfied' or 'quite satisfied' with the module, indicating a greater awareness of the importance of a multi-sensory approach to accommodate the different learning styles of their students. The methodology used to facilitate a shift in thinking is a combination of motivational interviewing, solution-oriented counselling, and ontological coaching (Miller \& Rollnick, 2002; O’Hanlon \& Weiner-Davis, 1998; The Newfield Network, 1996). The techniques include using open-ended questions, 
listening reflectively, challenging assumptions and expectations, and active learning strategies. As a result, TAs have expressed a better understanding of inclusive teaching and its benefits to all students, thus removing the fear of having to provide individualized instruction for every student with a hidden disability. In addition, TAs' comments suggest that they have developed greater confidence when working with diverse learners who can be seen to add value to the classroom and not to be feared. A number of TAs stayed to discuss issues related to learning disabilities after the formal conclusion of the module.

Anecdotal feedback from faculty members has also been positive. This is particularly rewarding, since not everyone welcomed the introduction of a mandatory teaching development session for TAs, initiated by the Associate Dean responsible for teaching and learning in the Faculty. We became aware that some senior faculty members felt that their doctoral students should be exempt from the program, as there was very limited time to complete their doctoral research work. Apparently many program participants had mentioned to the senior faculty members that the program was useful to them, and that recently the senior faculty members have shown more support for the program. However, further investigation is necessary to identify the level of support for the program among the faculty, and the impact this program may have had on TAs' performance in class.

In the early plans for the program, many stakeholders were of the view that the emphasis should be on communication issues related to lack of proficiency in the English language; most TAs in engineering were international students and many were from non-English speaking backgrounds. While the language difficulties and adjustment to different cultures are still an important part of the program, the interest generated during discussions of learning disabilities shows that there is a genuine need for its inclusion in the program. In order to create greater awareness of learning disabilities, a program for tenured faculty should be considered. This step, of course, requires long-term commitment from more senior faculty members.

\section{Conclusion}

The paper outlines an approach that was taken to promote awareness of learning disabilities among those who have the opportunity for close contact with individual students, i.e., the TAs. The primary purpose of the approach was to create a more inclusive teaching and learning environment. The initial skepticism that was evident among TAs and some faculty members, with regards to the program and in particular the inclusion of discussions on learning disability, has appeared to have receded. The program has been conducted before the start of every semester since its introduction at the beginning of 2007 . There is now more acceptance of the teaching development program as a whole, and the component on learning disabilities embedded in one of the program modules.

\section{References}

Australian Learning and Teaching Council. (2008). The RED report: The contribution of sessional teachers to higher education. Retrieved October 12, 2008, from http://www.cadad. edu.au/sessional/RED/docs/red_report.pdf

Australian Universities Teaching Committee. (2003). Training, support and management of sessional teaching staff: Final report. Retrieved October 12, 2008, from http://www.tedi.uq.edu.au/ SessionalTeaching/pdfs/Lit_review/Survey_ results.pdf

Beacham. N., \& Szumko, J. (2005). DyslexSim version 1.2 materials pack. Loughborough, UK: Loughborough University, English Language Study Unit.

Dearn, J., Fraser, K., \& Ryan, Y. (2002). Investigation into the provision of professional development for university teaching in Australia. Retrieved October 12, 2008, from http://www.dest.gov. au/NR/rdonlyres/D8BDFC55-1608-4845B172-3C2B14E79435/935/uni_teaching.pdf 
Dysievick, L. (2007). Reference guide: Faculty of engineering demonstrator teaching development program. Unpublished report, Centre for the Advancement of Learning and Teaching, Monash University, Melbourne, Australia.

Eaton Coull Learning Group. (2003). Transitions to postsecondary learning. Vancouver, BC: ECLG Learning and Publishing Group Production.

Felder, R., \& Silverman, L. (n.d.). Index of learning styles. Retrieved October 12, 2008, from http://www4.ncsu.edu/unity/lockers/users/f/ felder/public/ILSpage.html

Glaser, R. (1977). Adaptive education: Individual diversity and learning. New York: Holt, Rinehart and Winston.

Miller, W., \& Rollnick, S. (2002). Motivational interviewing: Preparing people for change. New York, NY: The Guildford Press

Monash University. (n.d.). Inclusive teaching for diverse learners. Retrieved October 12, 2008, from http://www.monash.edu.au/lls/ inclusivity/

Mortimore, T. (2003). Dyslexia and learning style: A practitioner's handbook. London, UK: Whurr Publishers.

Norlander, K.A., Shaw, S.F., \& McGuire, J.M. (1990). Competencies of postsecondary personnel servicing students with learning disabilities. Journal of learning Disabilities, 23(7), 426-432.

O’Hanlon, W.H. \& Weiner-Davis, M. (1998). In search of solutions: $A$ new direction in psychotherapy. New York, NY: W. W. Norton and Co.

The Newfield Network. (1996). Mastering the art of professional coaching: Newfield certified coach training program. San Francisco, USA.

\section{Biographies}

Elizabeth Santhanam is a Senior Lecturer at the Centre for the Advancement of Learning and Teaching, and has been coordinating the teaching development program for Engineering Teaching Assistants of Monash University, Australia. Her scholarly interests include coordinating sessional staff support, teaching development through structured programs, supporting teaching development of staff new to the University, and motivating high quality learning and teaching.

Wendy Paulusz is a Lecturer at the Centre for the Advancement of Learning and Teaching in Monash University, Australia. She is coordinating the 'Inclusive Practices Project' and works closely with the Disability Liaison Unit. Her scholarly interests include offering workshops to faculty and general staff on how to develop and apply innovative inclusive teaching approaches and delivering education, training, and change management sessions on diversity in the workplace to associated education organisations. 